\title{
MOTIF TEKSTIL SEBAGAI VALUE PROPOSITION KOLEKSI BRAND FESYEN YANG MARKETABLE
}

\author{
Paulina Tjandrawibawa \\ (Email: paulina.tjandrawibawa@ciputra.ac.id) \\ Desain Komunikasi Visual \\ Fakultas Industri Kreatif \\ Universitas Ciputra \\ UC Town, Citraland Surabaya, Indonesia
}

\begin{abstract}
ABSTRAK
Meningkatnya perkembangan industri fesyen di Indonesia dari tahun ke tahun membuat kompetisi antar brand fesyen juga semakin meningkat. Badan Ekonomi Kreatif Indonesia (Bekraf) memproyeksikan pelaku industri fesyen hingga tahun 2020 akan bertambah sebanyak 8,4 juta. Pelaku di industri fesyen ini didominasi oleh anak muda. Dengan banyaknya brand fesyen yang bermunculan tentunya sebuah brand membutuhkan nilai lebih atau yang biasa disebut dengan value proposition untuk tampil menonjol dan marketable. Dalam tulisan ini akan dibahas bagaimana motif grafis pada tekstil bisa menjadi value proposition untuk brand fesyen dalam menciptakan produk yang marketable. Metode penelitian ini akan dipaparkan melalui metode kualitatif berupa wawancara langsung dengan pemilik brand fesyen serta didukung dengan studi literatur dan observasi. Diharapkan dengan adanya penulisan ini, pelaku bisnis industri fesyen mendapat pemahaman konsep desain dalam merancang koleksi untuk brand yang pada akhirnya akan memiliki value proposition.
\end{abstract}

Kata Kunci: fesyen; motif; pattern; tekstil; value proposition.

\begin{abstract}
Fashion industry in Indonesia is increasing from year to year and so does the competition between fashion brands. The Indonesian Creative industry players by 2020 to grow by 8.4 million and dominated by young adults. With the many fashion brands that emerge, a brand needs more value propositions to make their product stand out and marketable. This journal will present how graphic motif on textile can be used by fashion brands as their product's value proposition and convert it into marketable products. Research method will be presents through qualitative method in the form of direct interview with fashion brand owner and supported by literature study and observation. This writing aims to help fashion business owners to comprehend the design concept as value position for their collection.
\end{abstract}

Keywords: fashion, motif; pattern; textile; value proposition 


\section{PENDAHULUAN}

Dunia fesyen di Indonesia mengalami perkembangan yang sangat pesat. Menurut press-release yang dikeluarkan oleh Badan Ekonomi Kreatif Indonesia (BEKRAF) pada bulan Agustus 2016, industri fesyen adalah salah satu dari tiga penyumbang terbesar pertumbuhan ekonomi Indonesia dari sektor ekonomi kreatif. Adapun nilai pasar yang dicapai oleh industri fesyen adalah 180 triliun rupiah per tahun. Badan Pusat Statistik Indonesia juga menunjukkan data sektor fashion memberikan kontribusi sebesar 18,15\% pada pertumbuhan ekonomi di Indonesia.

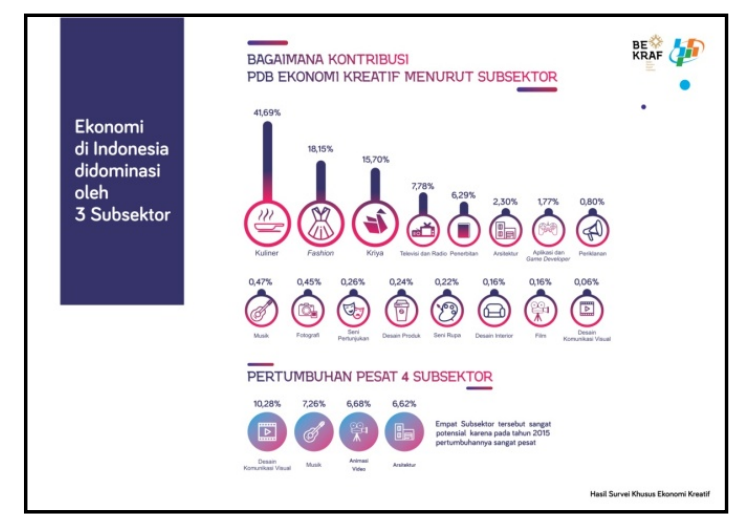

Gambar 1. Kontribusi ekonomi kreatif berdasar subsektor Sumber: Bekraf dan Badan Pusat Statistik

Wakil Kepala BEKRAF, Ricky J. Pesik, pada wawancaranya kepada sebuah media di bulan April 2017, menyatakan bahwa faktor utama yang mendorong pertumbuhan industri kreatif di Indonesia adalah kualitas SDM yang terus berkembang dan didominasi anak muda. Hal ini juga didukung oleh data dari Badan Pusat Statistik yang menunjukkan subsektor dengan proporsi terbesar pada fashion sekitar $42,83 \%$.

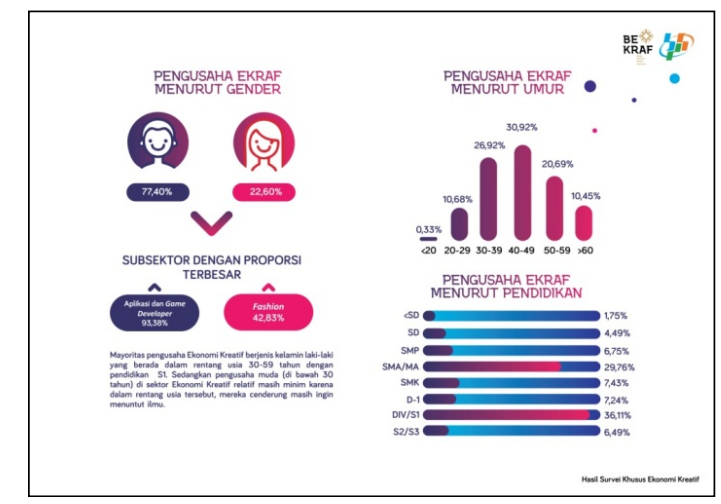

Gambar 2. Profil pengusaha ekonomi kreatif Sumber: Bekraf dan Badan Pusat Statistik 
Melalui data tersebut, dapat diprediksi bahwa pangsa pasar untuk industri fesyen di kalangan muda memiliki peluang yang menjanjikan hingga beberapa tahun ke depan. Namun, pada saat yang sama menunjukkan persaingan bisnis fesyen yang semakin ketat. Semakin ketatnya persaingan dunia bisnis fesyen untuk merebut pasar mengharuskan pebisnis untuk memiliki value proposition yang bisa ditawarkan kepada konsumen.

Memiliki nilai pembeda atau nilai lebih dari produk yang ditawarkan sangatlah penting untuk keberlangsungan sebuah bisnis. Ketika pasar kian kompetitif dan banyak bisnis serupa yang bermunculan, tentunya pelaku bisnis harus jeli memberi nilai lebih produk yang ditawarkan agar mampu bersaing dan bertahan di pasar yang dituju. Seifert dan Chattaraman (2017) juga mengemukakan bahwa: "konsumen saat ini dibanjiri dengan banyaknya pilihan produk sehingga pemilik merk kian membutuhkan penciptaan produk dengan desain superior agar bisa memiliki nilai pembeda dan mencapai keuntungan kompetitif (Bloch, 1995)."

Menurut pendapat Kotler (2003), para pembeli akan membeli produk yang mereka anggap menawarkan customer delivered value yang tertinggi. Hal ini mengenai pemenuhan kebutuhan konsumen yang terdiri dari kebutuhan fungsional yaitu kebutuhan berdasarkan daya guna sebuah produk, kebutuhan psikologis yaitu kebutuhan berdasarkan pemuasan pribadi (emosional) terhadap sebuah produk, atau kombinasi dari kedua hal tersebut. Namun, pada intinya produk yang akan dipilih konsumen adalah produk yang dapat memberikan value lebih kepada konsumen dibandingkan dengan produk sejenis lainnya.

Penciptaan value suatu produk dihasilkan dengan menawarkan sejumlah keunggulan produk dalam bentuk berwujud maupun tidak berwujud. Hal ini meliputi desain, warna, ukuran, kemasan dan sebagainya. Sedangkan atribut yang tidak berwujud di antaranya harga, jasa, layanan dan kualitas (Kotler, 2002: 127).

Merujuk dari latar belakang masalah yang telah dijabarkan, peneliti tertarik untuk meneliti motif tekstil sebagai value proposition koleksi brand fesyen yang marketable.

\section{METODE PENELITIAN}

Pada penelitian ini akan digunakan metode deskriptif kualitatif yang digunakan untuk mengeksplorasi dan memahami masalah sosial dari segi individual atau grup. Proses penelitian mencakup membuat pertanyaan dan prosedur serta pengumpulan data yang kemudian 
diinterpretasikan oleh penulis (Creswell, 2009). Metode kualitatif memiliki dua karakteristik utama. Yang pertama dan terutama adalah berfokus pada fenomena yang terjadi secara alami di "dunia nyata". Yang kedua, terlibat dalam mempelajari fenomena di keseluruhan kompleksitasnya (Leedy dan Ormrod, 2005). Metode ini sesuai untuk mengetahui pandangan dari beberapa individu yang memiliki pengalaman terhadap perilaku pembeli dalam membeli pakaian sehingga dapat membantu pencapaian hasil riset yang valid.

Tahapan awal dalam penelitian ini adalah mendokumentasikan pengamatan terhadap koleksi brand fesyen global di mall untuk mengetahui jenis pattern pakaian yang populer. Pengamatan juga dilakukan secara online melalui Instagram serta platform e-commerce. Hal ini dilakukan untuk mengetahui jenis style dan tren yang diinginkan oleh konsumen yang memiliki daya jual. Selain pengamatan terhadap koleksi brand fesyen, dilakukan juga pengamatan terhadap tren fesyen terkini secara online dari website yang sering digunakan oleh desainer fesyen untuk acuan tren, sebagai contoh www.wgsn.com (Payne, 2016).

Hasil penelitian secara offline dilakukan secara langsung dengan mendatangi beberapa toko brand terkemuka seperti Zara dan H\&M, karena menurut Walter Loeb, ahli bidang perkembangan retail sekaligus kontributor Forbes, kedua brand tersebut adalah brand retail besar di dunia. Hal yang sama juga dikemukakan oleh Carsten Keller dan rekan dalam artikel yang ditulis untuk McKinsey, perusahaan konsultasi global. Jacqueline Yuen, ahli ekonomi dari Hong Kong Trade Development Council, juga menyatakan salah satu brand fesyen terkenal di kalangan pembeli Indonesia adalah Zara. Sedangkan, H\&M mampu melihat potensi pasar yang menjanjikan di Indonesia. Baik Zara maupun H\&M juga memiliki koleksi pakaian yang menggunakan motif seperti motif flora dan geometris yang cukup sering muncul secara berkala di koleksi terbaru mereka.

Pada online store, dilakukan pengamatan terhadap merek lokal, Calla-Atelier. Brand ini didirikan oleh fashion blogger Indonesia terkenal, Olivia Lazuardy. Menurut artikel Jakarta Post, brand ini juga dipilih oleh Zalora, fashion e-commerce terbesar di Asia dan yang paling banyak digunakan di Indonesia, untuk berkolaborasi bersama di Zalora Designer Project 2.0. 

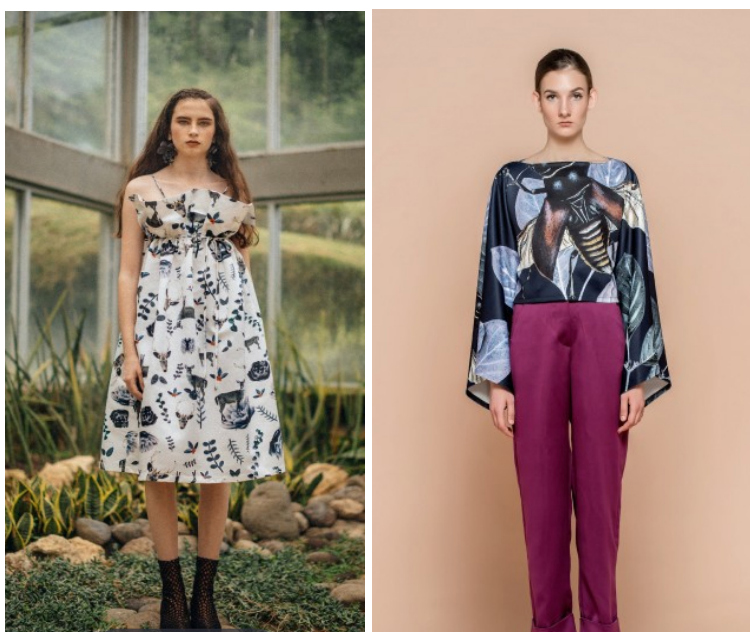

Gambar 3. Koleksi Calla-Atelier Sumber: www.Calla-Atelier.com

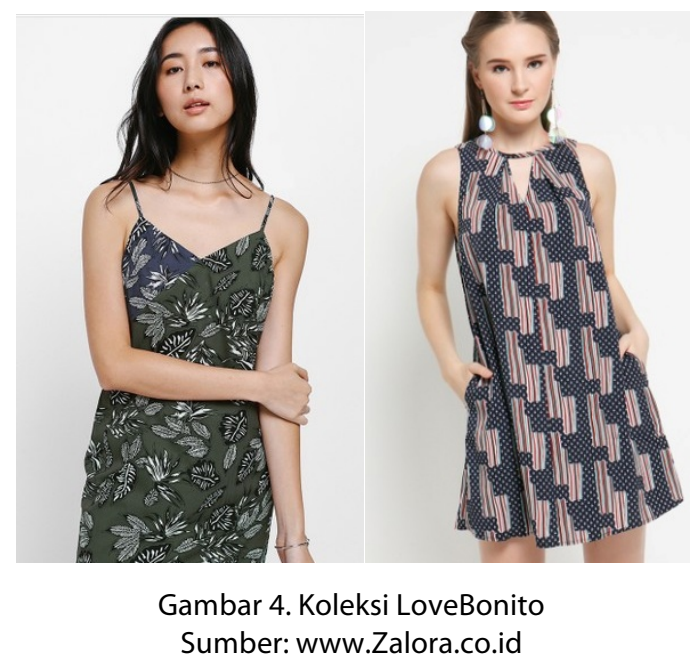

Selain brand lokal, pengamatan juga dilakukan ke brand Singapura yang sudah established di Indonesia yaitu Love Bonito karena brand ini termasuk salah satu brand yang ada di kategori brand paling top di website Zalora Indonesia. Beberapa koleksi Love Bonito yang menggunakan motif juga terjual habis.

Setelah melakukan pengamatan yang telah didokumentasikan, langkah selanjutnya adalah melakukan wawancara terhadap pelaku bisnis di bidang fesyen yang telah memiliki pengalaman dalam melihat tren pasar. Adapun pertanyaan wawancara berkisar pada jenis motif kain dan warna untuk koleksi brand fesyen yang disukai oleh pasar. Berdasarkan wawancara yang berisi opini dan saran dari narasumber ahli tersebut, dilakukan pembuatan desain motif kain yang dimanipulasi secara digital agar terlihat siluetnya dalam bentuk pakaian 
dan divoting oleh 100 wanita usia 20-35 tahun untuk mendapatkan validasi pasar.

\section{PEMBAHASAN}

Seiring dengan ketatnya persaingan di industri fesyen, brand fesyen lokal yang didominasi oleh generasi muda harus mampu menawarkan nilai lebih dibanding kompetitor agar dapat bertahan di pasar. Menurut Gotzsch (2000), di pasar yang semakin kompetitif sangatlah penting untuk sebuah produk memiliki kualitas estetika dan semantik. Fesyen dipenuhi oleh keinginan untuk perubahan, saat ini segi estetika yang diinginkan oleh pasar adalah pattern dan warna (Fogg, 2006).

Kedua pernyataan tersebut didukung oleh McKinney dan Shin (2016) yang juga mengemukakan bahwa: "konsumen membeli pakaian berdasarkan pada empat kriteria yaitu: (a) estetika (warna atau motif, styling, kain, keunikan, dan penampilan), (b) kegunaan, (c) kualitas, dan (d) ekstrinsik (harga, merk, dan kompetisi) (Eckman, Damhorst, dan Kadolph, 1990)." BEKRAF sebagai badan yang bertanggung jawab terhadap perkembangan ekonomi kreatif di Indonesia agar memiliki daya saing di dunia internasional, mengeluarkan tren fesyen 2017 yang dominasinya masih terletak pada jenis pattern dan warna kain.

\section{Motif Textil}

Motif untuk tekstil pada umumnya berupa ilustrasi grafis yang memiliki berbagai macam bentuk mulai dari abstrak hingga realis. Ilustrasi-ilustrasi inilah yang dipakai oleh brand fesyen untuk menarik perhatian calon konsumen yang menggunakan pakaian sebagai sarana mengeskpresikan diri (Barnard, 2002). Menurut Abraham-Murali dan Littrell, ilustrasi juga termasuk dalam salah satu aspek estetika ketika calon pembeli mengevaluasi pakaian karena motif pada kain biasanya berupa ilustrasi dan memiliki warna (seperti yang dikutip oleh McKinney dan Shin, 2016).

Hasil pengamatan secara online dan offline, berikut adalah motif dan warna yang sedang diminati oleh masyarakat pada umumnya: 


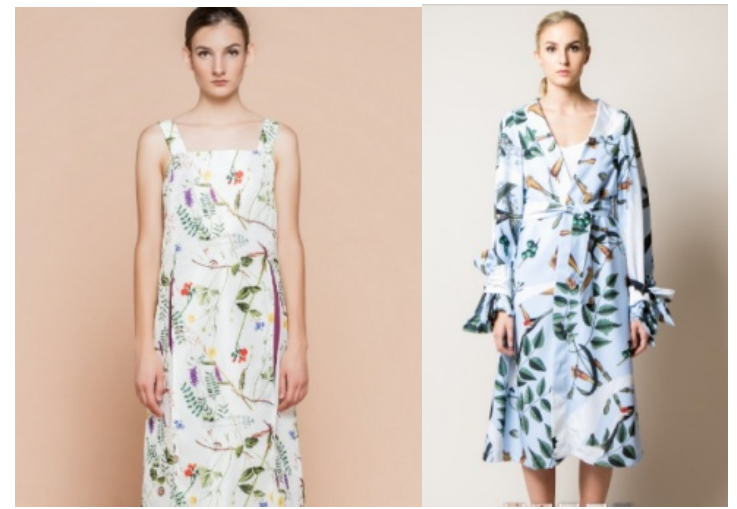

Gambar 5. Koleksi pakaian rancangan Olivia Lazuardy Sumber: www.calla-atelier.com

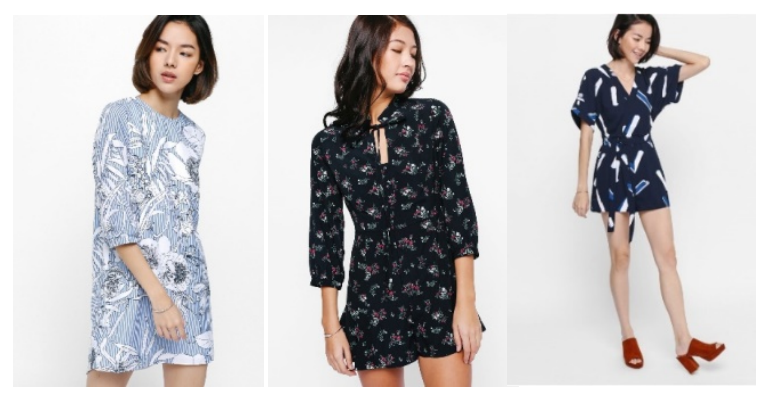

Gambar 6. Koleksi pakaian milik brand Love Bonito yang populer Sumber: www.lovebonito.com

Adapun trend fashion yang diprediksi oleh WGSN dan BEKRAF adalah sebagai berikut:

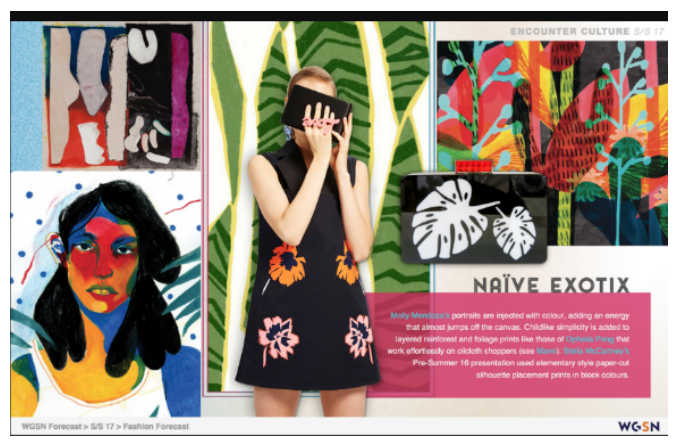

Gambar 7. Salah satu trend forecast oleh WGSN Sumber: www.wgsn.com 


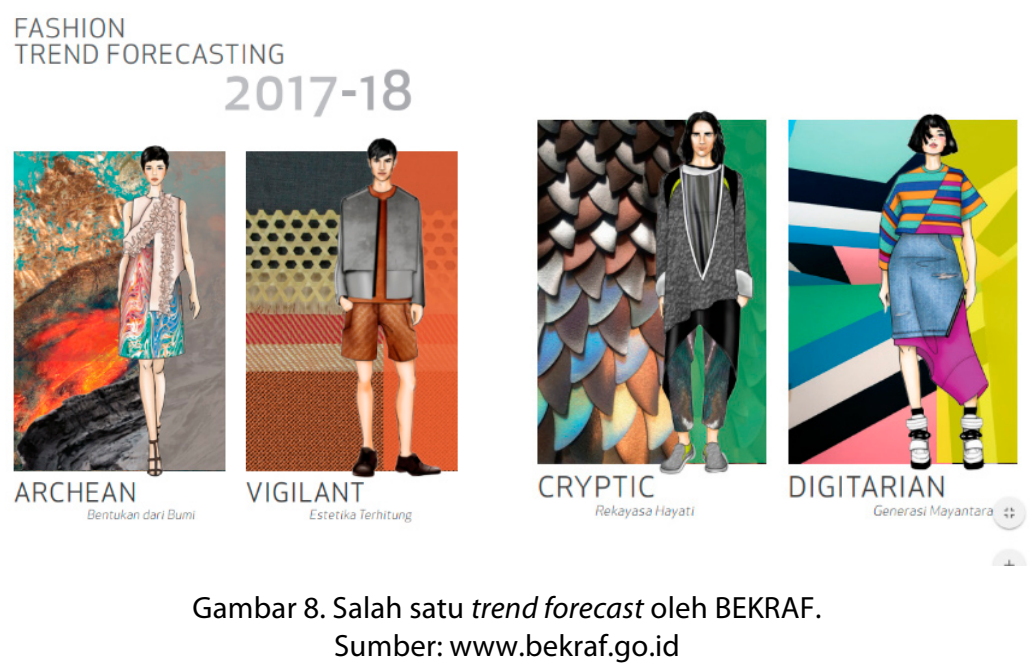

Dari hasil pengamatan secara offline dan online dapat ditarik kesimpulan bahwa motif yang cukup digemari dan masih masuk dalam tren tahun ini adalah flora dan geometris.

Selain dari pengamatan, hasil wawancara juga dilakukan terhadap fashion brand owner dan fashion designer consultant untuk memperkuat hasil pengamatan yang dilakukan secara offline dan online. Yoanita Tahalele, pemilik brand fesyen, Flying Feather, yang telah berdiri sejak 2011 dan e-commerce khusus pakaian dari desainer-desainer lokal mengemukakan bahwa saat ini masyarakat cenderung memilih warna nude dalam membeli busana. Namun, untuk pembeli wanita yang berasal dari Surabaya, warna merah muda sangat disukai. Dari segi motif kain, motif berbentuk geometris sedang disukai akan tetapi masyarakat pada umumnya cenderung mengikuti tren sehingga preference mereka berubah-ubah.

Hal senada diungkapan oleh Fashion Designer Consultant, Truly Hutagalung, yang telah memiliki pengalaman selama lebih dari 10 tahun di bidang fesyen dengan kliennya adalah brand lokal dan internasional. Warna netral dan motif geometris masih disukai oleh masyarakat, terutama wanita Jakarta. Untuk motif floral lebih disukai oleh orang dari daerah. Sedangkan untuk industri fesyen pada umumnya, baik warna maupun motif kain akan selalu mengikuti tren yang sedang ada agar bisa menarik minat pembeli.

Hasil dari pengamatan dan wawancara tersebut, selanjutnya dilakukan voting pada tiga jenis desain motif kain yang kemudian dimanipulasi secara digital agar terlihat siluetnya dalam bentuk pakaian (untuk gambar A dan B). Desain motif gambar A adalah motif geometris milik 
brand fesyen online store luar negeri yang warnanya diedit oleh penulis, desain motif gambar B adalah motif floral yang diambil dari sumber gambar internet free-royalty yang motif ini serupa dengan motif biasa dipakai oleh beberapa brand lokal. Desain motif $\mathrm{C}$ adalah motif bergambar binatang yang merupakan produk asli dari salah satu brand yang cukup dikenal di Indonesia. Berikut penampilan ketiga motif tersebut:

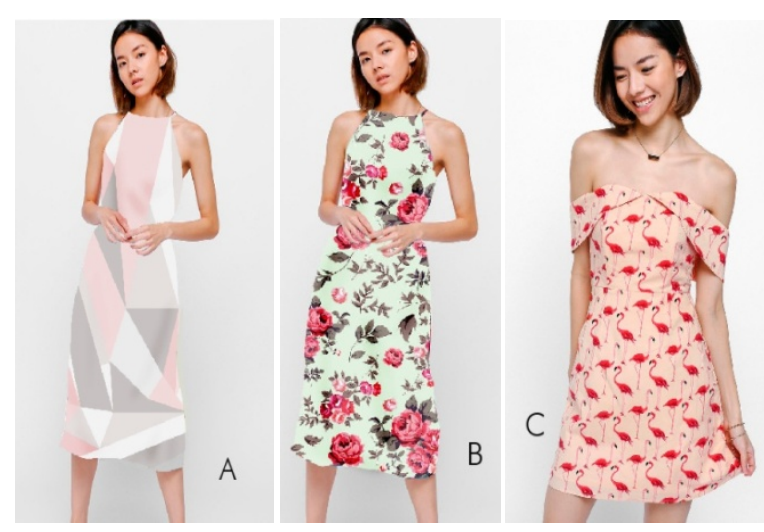

Gambar 9. Tiga jenis desain motif kain sebagai voting Sumber: penulis

Gambar ini ditunjukkan kepada 100 responden wanita berusia 20-34 tahun. Sebanyak 80\% memilih motif gambar A, 19.7\% motif gambar C, dan $0.3 \%$ motif gambar $B$.

\section{Value Proposition}

Osterwalder dan Pigneur (2014:23) menyatakan bahwa value proposition menciptakan nilai untuk segmen konsumen melalui panduan elemen-elemen berbeda yang dapat melayani kebutuhan segmen tersebut. Elemen-elemen yang dapat berkontribusi pada penciptaan nilai konsumen, yaitu sifat baru, kinerja, penyesuaian, menyelesaikan pekerjaan, desain, merk/status, harga, pengurangan biaya, pengurangan risiko, kemampuan dalam mengakses, serta kenyamanan dan kegunaan. Desain merupakan elemen penting namun sulit diukur. Sebuah produk mungkin menonjol karena desainnya superior. Dalam industri fesyen dan elektronik konsumen, desain bisa menjadi bagian penting dari proposisi nilai.

Osterwalder dan Pigneur (2014) menyatakan bahwa value proposition harus belajar melalui seluruh value life cycle. Elemen value dapat dibuat di masing-masing lima tahap value life cycle. Tahap ini adalah sebagai berikut: 
1. Value creation: Pandangan tradisional dari proses penciptaan value tidak memungkinkan konsumen untuk mengambil bagian dalam merasakan value. Pemasaran dan penelitian serta pengembangan bertanggung jawab untuk menambahkan value pada tahap ini didasarkan pada data historis dan observasi. Data observasi dan wawancara mengungkapkan bahwa motif bisa menjadi value creation dan akan menjadi tren.

2. Value appropriation: Value dapat dibuat dalam tahap ini dengan mengembangkan, meningkatkan, dan memfasilitasi pengalaman membeli konsumen. Hal ini dapat dilakukan dalam dua langkah, pertama meningkatkan bagaimana transaksi dilakukan dan kedua dengan membuat konsumen merasa puas.

3. Value consumption: Inti value proposition, pada tahap ini konsumen melihat dan merasakan value melalui penggunaan aktual dari produk atau layanan. Pada tahap ini value dapat dibuat melalui setumpuk manfaat yang terkait dengan produk atau jasa. Hal ini dapat diperbaiki melalui pengamatan dan menghasilkan umpan balik.

4. Value renewal: Tahap ini adalah ketika value berakhir atau selesai, misalnya ada penggantian atau perbaikan untuk produk fashion yang telah dibeli bila ada kerusakan. Value dapat dibuat pada tahap ini dengan menambahkan lebih banyak manfaat dan fitur untuk produk atau layanan dalam proses perpanjangan.

5. Value transfer: Tahap akhir dari siklus hidup value adalah tahap ketika konsumen tidak bisa lagi memperoleh value. Namun, value dapat dibuat dalam saluran baru, memperoleh manfaat dengan mentransfer value.

Hasil penelitian menyatakan bahwa konsumen yang membeli sebuah item fesyen mempunyai kecenderungan memilih berdasarkan atribut estetika dibandingkan kegunaan ataupun fungsi.

Hal ini dibuktikan pada sebuah pembelajaran point of purchase yakni ketika konsumen wanita diminta untuk mengingat atribut yang dipertimbangkan dalam membeli item fesyen, konsumen tersebut menjawab warna, motif, gaya, dan kain dibandingkan kegunaan atau fungsinya sebagai penutup tubuh (Eckman, Damhorst, dan Kadolph, 1990). Sebagaimana halnya dalam survei yang telah dilakukan dalam penelitian ini terhadap 100 responden yang lebih menyukai motif gambar geometris. 
Selain untuk sarana mengekspresikan diri, penggunaan ilustrasi yang berestetika tinggi juga akan membantu penjualan koleksi pakaian. Seperti yang dinyatakan dalam Mandoki (2007) bahwa kebutuhan konsumen untuk memiliki barang dengan estetika desain tinggi sangat terasa untuk kategori pakaian karena dapat merangsang perasaan hedonic yang tinggi (Byun and Sternquist, 2011). Niinimaki (2014) juga berpendapat bahwa: "bisnis dan marketing di industri fesyen hanya menggunakan aspek kecantikan dan estetika untuk menarik perhatian konsumen.

Estetika bergantung pada konteks yang dimaksud tapi salah satu kemungkinannya adalah dengan mengasosiasikan kenikmatan yang dirasakan oleh pengamat ketika persepsi terhadap sebuah visual timbul secara langsung dan sederhana (Naukkarinen, 2007). Motif dan warna berkaitan satu dengan lainnya dan ketika mereka dikombinasikan akan mampu memiliki kekuatan untuk menarik perhatian secara emosional.

Obinnim dan Pongo (2015) berpendapat bahwa seorang desainer yang menggunakan elemen dan prinsip desain dalam pembuatan pakaian akan menghasilkan karya yang memiliki kualitas estetika tinggi dan bisa diapresiasi oleh konsumen dan orang yang melihat. Tanpa adanya pengetahuan dan pengertian akan elemen dan prinsip desain, seorang desainer tidak akan dapat membuat garmen yang memiliki estetika yang bagus.

\section{PENUTUP}

Meningkatnya pasar fesyen di Indonesia merupakan sebuah peluang usaha dan juga menumbuhkan Industri fesyen. Persaingan industri fesyen dalam menarik konsumen, membuat para desainer harus memikirkan bagaimana menciptakan sebuah brand fesyen yang bisa memberikan value proposition dan dapat meningkatkan penjualan.

Dalam penelitian ini yang menggunakan teori Osterwalder tentang value proposition dapat disimpulkan bahwa penciptaan value pada sebuah brand fesyen sangat penting, karena konsumen sekarang ini membeli sebuah produk fesyen bukan hanya sebagai kegunaan atau fungsi saja tetapi sudah menyangkut aspek atribut estetika.

Hal ini sejalan dengan hasil studi literatur dan wawancara terhadap narasumber, sumber trend forecast, serta pengamatan secara online dan offline, bahwa motif memiliki fungsi sebagai value 36 
proposition sehingga dapat menarik perhatian calon pembeli di antara brand lainnya. Seperti yang dikatakan Osterwalder dan Pigneur (2014:23) desain merupakan salah satu elemen penting yang bisa memberikan value proposition. Sebuah produk mungkin menonjol karena desainnya superior. Ini sesuai dengan survey yang dilakukan terhadap 100 responden yang lebih memilih dan menyukai motif geometris.

Dalam industri fesyen dan elektronik konsumen, desain bisa menjadi bagian penting dari proposisi nilai. Maka dari itu dapat disimpulkan bahwa value proposition seperti motif tekstil pada brand fesyen dapat menjawab problem atau mengatasi persaingan dunia bisnis fesyen, dan meningkatkan penjualan produk fesyen serta memenuhi kebutuhan konsumen akan sesuatu yang baru.

\section{DAFTAR PUSTAKA}

Bekraf. (2016, Agustus 29). Pendukungan subsektor fesyen. Pesan disampaikan dalam http://www.bekraf.go.id/berita/page/10/press-release-pendukungan-subsektor-fashion

Bekraf. (2016, Desember 25). Greyzone: Trend Forecasting 2017-18. Pesan disampaikan dalam http://www.bekraf.go.id/berita/page/12/launching-indonesia-trend-forecasting-2017

Bloch, H. Peter. (1995). Seeking the ideal form: Product design and consumer response - Journal of Marketing, 59 (3). Diunduh 1 Juni 2017 dari www.eng.waterloo.ca/Jzelek/teaching/syde361/bloch.pdf

Byun, S. E., and Sternquist, B. (2011). Fast fashion and in-store hoarding: The drivers, moderator, and consequences - Clothing and Textiles Research Journal, 29 (3). Diunduh 15 Mei 2017 dari https://scholars.opb.msu.edu/en/publications/fast-fashion-and-in-store-hoardingthe-drivers-moderator-and-cons- 4 .

Cheung, V. (2007). Fashion Wonderland. Hong Kong: Victionary.

Creswell, J.W. (2009). Research Design. California: SAGE Publications.

Eckman, M., Damhorst, L. D., and Kadolph, J. S. (1990). Toward a model of the in-store purchase decision process: Consumer use of criteria for evaluating women's apparel -Clothing and Textiles Research Journal, 8. Diunduh 14 Mei 2017 dari DOI: 10.1177/0887302X9000800202.

Fogg, M. (2006). Print in Fashion. London: Batsford

Gotzsch, J. (2000). Beautiful and Meaningful Products. Makalah dipresentasikan pada

The Politecnico di Milano Conference, Design plus Research, Milan, Italia.

Justema, W. (1976). Pattern, A Historical Panorama. Boston: New York Graphic Society. 
Keller, Carsten, et al. (2014, September). Succeeding in tomorrow's global fashion market. Pesan disampaikan dalam https://www.mckinsey.com/business-functions/marketing-andsales/our-insights/succeeding-in-tomorrows-global-fashion-market

Leedy, P. D. and Ormrod, J. E. (2005). Practical Research. Planning and Design ( $8^{\text {th }}$ ed.). New Jersey, USA: Pearson Prentice Hall Publications.

Lockwood, T. (2010). Design Thinking: Integrating Innovation, Customer Experience and Brand Value. New York: Allworth Press.

Loeb, Walter. (2015, Maret 30). Zara leads in fast fashion. Pesan disampaikan dalam https://www.forbes.com/sites/walterloeb/2015/03/30/zara-leads-in-fastfashion/\#6933b74b5944

Kotler, Philip. (2002). Manajemen Pemasaran. Buku 1 Edisi kesebelas. Jakarta: Erlangga.

Mandoki, K. (2007). Everyday aesthetics: Prosaics, the play of culture and social identities. Aldershot: Ashgate.

McKinney, E., and Shin, E. (2016). Exploring criteria consumers use in evaluating their online formal wear rental experience: a content analysis of online reviews - Clothing and Textiles Research Journal, $34 \quad$ (4). Diunduh pada 1 Juni 2017 dari www.eonyoushin.com/uploads/4/4/8/9/44890499/mckinney_shin_2016_.pdf

Naukkarinen, O. (2007). Art of the Environment. Helsinki: Okka.

Niinimaki, K. (2014). Green Aesthetic in Clothing - Artifact, 3 (3), 3.1-3.13.

Obinnim, E. and Pongo, N. (2015). The appropriate use of elements and principles of design in garment construction by dressmakers and tailors in the ho municipality of Ghana - Journal of Innovative Research in Science, Engineering and Technology, 4(4). Diunduh 3 Juli 2017 dari https://www.ijirset.com/upload/2015/april/7_The_appropriate.pdf.

Osterwalder, A dan Pigneur, Yves. (2014). Business Model Generation. Alih bahasa oleh Natalia Ruth Sihandrini. Jakarta: PT Elex Media Komputindo.

Payne, Alice. (2016). Inspiration sources for Australian fast fashion design: tapping into consumer desire - Journal of Fashion Marketing and Management, 20 (2). Diunduh 28 Agustus 2017 dari https://doi.org/10.1108/JFMM-12-2014-0092.

Seifert, Christin, and Chattaraman, Veena., (2017). Too new or too complex? Why consumer's aesthetic sensitivity matters in apparel design evaluation - Journal of Fashion Marketing and Management, 21 (2). Diunduh 1 Juni 2017 dari https://doi.org/10.1108/JFMM-10-2016-0092. 
Wreksono, Asmara (2016, September 30). Fashion e-commerce firm collaborates with young Indonesian designers. Pesan disampaikan dalam http://www.thejakartapost.com/ life/2016/09/30/fashion-e-commerce-firm-collaborates-with-young-indonesiandesigners.html

Yuen, Jacqueline (2014, Februari 27). Targeting Indonesia's female shoppers - prime products and channels. Pesan disampaikan dalam http://economists-pick research.hktdc.com/businessnews/article/Research-Articles/Targeting-Indonesia-s-female-shoppers-prime-productsand-channels/rp/en/ 1/1X000000/1X09WODN.htm 